\title{
Para Além da Concepção Binária Cis-heternormativa: a Psicanálise Interrogada pelas Diversidades Sexuais e de Gênero
}

\author{
Luciana Balestrin Redivo Drehmer ${ }^{1}$ \\ ${ }^{1}$ Pontifícia Universidade Católica, RS, Brasil.
}

\author{
Carolina Neumann de Barros Falcão ${ }^{1}$ \\ ${ }^{1}$ Pontifícia Universidade Católica, RS, Brasil.
}

\begin{abstract}
Resumo: Freud debruçou-se, ao longo de toda sua incansável produção teórica, sobre a complexidade da sexualidade humana e seus desdobramentos. A partir da experiência da fundação do "Laboratório de Sexualidade, Gênero e Psicanálise" no Serviço de Atendimento e Pesquisa em Psicologia (SAPP) - Serviço-Escola do Curso de Psicologia da Pontifícia Universidade Católica do Rio Grande do Sul (PUCRS) - pretende-se, neste artigo produzir tensionamentos teóricos a respeito dos paradigmas metapsicológicos que, por muito tempo, sustentaram o pensamento psicanalítico. Revela-se o grande impacto do reconhecimento da falta teórica e técnica da Psicanálise, que sustentada historicamente por uma lógica binaria e cis-heteronormativa, não pôde dar conta de compreender as múltiplas formas de exercício da sexualidade. Por outro lado, entende-se que a (re)construção de normas faz da Psicanálise um instrumento vigoroso na escuta de modos de sexualidade e produção de subjetividades. Apoiado em constructos fundamentais, este trabalho propõe-se seguir com a sustentação metapsicológica da alteridade como acesso ao estatuto das diferenças nas relações do Eu e com os outros.
\end{abstract}

Palavras-chave: Psicanálise, Metapsicologia, Sexualidade, Gêneros, Alteridade.

\section{Beyond the Binary and Cis-heteronormative Conception: Psychoanalysis Interrogated by Sexual and Gender Diversities}

\begin{abstract}
Throughout his tireless theoretical production, Freud looked at the complexity of human sexuality and its development. From the experience of founding the "Laboratório de Sexualidade, Gênero e Psicanálise" at the Psychological Care and Research Service at the Pontifícia Universidade Católica do Rio Grande do Sul (PUCRS) - this essay is intended to produce theoretical tensions regarding the metapsychological paradigms that for a long time sustained psychoanalytic thought. It reveals the great impact of the recognition of the psychoanalysis theoretical and technical lack, which, historically supported by a binary and cis-heteronormative logic, could not account for understanding the multiple forms of the exercise of sexuality. On the other hand, it is understood that the (re)construction of norms makes Psychoanalysis a powerful instrument in listening to modes of sexuality and production of subjectivities. Based on fundamental constructs, it is proposed to follow with the metapsychological support of alterity as access to the status of differences in self-relationships and with others.
\end{abstract}

Keywords: Psychoanalysis, Metapsychology, Sexuality, Gender, Alterity. 


\title{
Mas allá de la Concepción Binaria Cisheternormativa: el Psicoanálisis Interrogado por la Diversidade Sexual y de Género
}

\begin{abstract}
Resumen:Freud se inclinó, a lolargo de toda su incansable producción teórica, sobrela complejidad de la sexualidad humana y sus desdoblamientos. A partir de la experiencia de la fundación del "Laboratorio de Sexualidad, Género y Psicoanálisis" en el Servicio de Atención e Investigación en Psicología (SAPP) - Servicio-Escuela del Grado en Psicología de la Pontificia Universidad Católica del Rio Grande do Sul (PUCRS) - en este artículo se busca producir tensiones teóricas respecto de los paradigmas metapsicológicos que, por mucho tiempo, sostuvieron el pensamiento psicoanalítico. Se revela el gran impacto del reconocimiento de la falta teórica y técnica del Psicoanálisis, que sostenida históricamente por una lógica binaria y cisheteronormativa, no pudo contemplar la comprensión de las múltiples formas de ejercicio de la sexualidad. Por otro lado, se entiende que la (re)construcción de normas hace del Psicoanálisis un instrumento vigoroso en la escucha de modos de sexualidad y producción de subjetividades. Apoyado en constructos fundamentales, este trabajo se propone seguir con la sustentación metapsicológica de la alteridad como acceso al estatuto de las diferencias en las relaciones del Yo y con los demás.
\end{abstract}

Palabras clave: Psicoanálisis, Metapsicología, Sexualidad, Género, Alteridad.

"Repensar a psicanálise é uma forma de fazer justiça ao texto freudiano" (Sigal, 2017, p. 44).

A sexualidade é considerada tema central e estruturante para a Psicanálise e sempre produziu, no campo psicanalítico, inúmeras formulações teóricas. É por meio da sexualidade - e do encontro com o Outro - que o sujeito psíquico se constitui, tornando-se, para além de sua dimensão autoconservativa, um ser erógeno e desejante. Freud debruçou-se, ao longo de toda sua incansável produção teórica, sobre a complexidade da sexualidade humana e seus desdobramentos. Deixou, assim, como herança, uma teoria aberta, profunda e viva, capaz de (re)formular hipóteses a partir da cultura, do sujeito e da clínica.

Freud (1976a) produziu uma revolução epistemológica quando afirmou que a sexualidade é parcial, polimórfica e infantil. Desde 1905, tem-se, a partir dos aportes psicanalíticos, subsídios para pensar que a construção de uma psicossexualidade é, sempre, singular. Freud (1976a), desde seu ensaio sobre Sexualidade Infantil, compreendeu a sexualidade humana como perversa por não se submeter somente à genitalidade e por não estar direcionada à função reprodutiva. A sexualidade, para a Psicanálise, refere-se à busca constante e à vigência do prazer.

Em sua origem, a sexualidade é essencialmente traumática pela descoberta do outro, da alteridade e das diferenças sexuais. Inúmeros textos freudianos evidenciam o caminho difícil e necessário a ser traçado por todo sujeito psíquico a fim de integrar-se como único, dotado de vontades e capaz construir relações afetivas e capitalizar investimentos.

A tarefa de reconhecer-se a partir de um olhar próprio inicia-se no encontro com o Outro, o qual produz enunciados identificatórios que serão a base do Autoerotismo. Para que um sujeito possa identificar-se, é necessário que tenha sido identificado por um adulto cuidador capaz de investimento alteritário. Desde esse encontro primordial, um sujeito recebe e, então, constrói - diversas versões sobre si próprio, que partem dos cuidadores, dos estímulos do próprio corpo e do próprio sistema perceptivo. Existe, portanto, um árduo trabalho psíquico de fazer-se sujeito, no qual o capital narcísico e psicossexual são elementos centrais. Construir psiquicamente um Eu significa desenvolver condições de identidade, de autoestima e de capacidade de realizar investir psíquicos (Hornstein, 2009). Além disso, a construção primeira se transforma ao longo dos processos de complexização psíquica nos caminhos de subjetivação. O sujeito, em Psicanálise, é um constante devir.

Pensar as vicissitudes da psicossexualidade e do narcisismo foi tarefa de Freud e de muitos psicanalistas que o sucederam. De fato, encontra-se inúmeras problematizações acerca dos destinos da sexualidade, 
desde 1905 até os dias de hoje. Um dos aspectos de maior tensionamento diz respeito às organizações da sexualidade quanto à identidade sexual e à identidade de gênero. A principal crítica ao pensamento freudiano neste cenário refere-se a uma leitura masculina da sexualidade e à heterossexualidade como paradigma universal de saúde psíquica.

De forma a contribuir com a construção de conhecimento em Psicanálise e com a clínica psicanalítica dos diferentes arranjos de sexualidade, gênero e orientação sexual, foi fundado no Serviço de Atendimento e Pesquisa em Psicologia (SAPP) - Serviço-Escola do Curso de Psicologia da Pontifícia Universidade Católica do Rio Grande do Sul (PUCRS) - o "Laboratório de Sexualidade, Gênero e Psicanálise". A iniciativa partiu de duas psicanalistas, professoras e supervisoras de estágio em Psicologia Clínica no Serviço-Escola que se depararam com numerosas convocatórias em sala de aula sobre a temática da sexualidade e do gênero e a respectiva leitura psicanalítica. A partir dos questionamentos discentes quando apresentados, principalmente, aos pressupostos freudianos acerca do Complexo de Édipo e das construções da masculinidade e feminilidade, foi-se produzindo tensionamentos, (re)visitações e (re) construções teóricas nas docentes que culminaram na proposição do Laboratório. De fato, entende-se que foi no registro de alteridade representada pelos alunos estranhos à Psicanálise que se deu a brecha de criação e de transformação na Psicanálise transmitida na Universidade.

O projeto se respalda nos 45 anos de existência do SAPP e é formado, atualmente, por duas professoras de graduação, um professor de pós-graduação e 13 alunos de graduação, todos de Psicologia. Inspirado na ideia de Pierre Fedida ao fundar o Laboratório de Psicopatologia Fundamental, o projeto recebeu o nome de Laboratório, não por se tratar de um espaço de ciência experimental, mas, sim, por dizer respeito a um espaço de produção de saber, no qual o método clínico permite encontrar o singular e a palavra que o sustenta. Berlinck (2000), a referir-se ao Laboratório de Psicopatologia Fundamental afirma que Laboratório é um lugar de trabalho (labor), necessitando não apenas a existência de um espaço físico que vai mas, também, um enquadre institucional e, fundamentalmente, um espaço mental no qual o que se vivencia na prática clínica possa ser alvo de um trabalho de pensamento que é posto em palavras. Conforme o autor, o Laboratório - esse espaço mental - deve ser constantemente recriado e é frequentado por pesquisadores e clínicos que dele queiram fazer parte.

O "Laboratório de Sexualidade, Gênero e Psicanálise" tem dois objetivos principais. O primeiro eixo diz respeito à produção de conhecimento e à transmissão da Psicanálise - revisitando e tensionando conceitos metapsicológicos fundamentais com os temas da sexualidade e do gênero. Já o segundo eixo articula-se à extensão, oferecendo atendimento gratuito à população LGBTQI+ com demandas de sofrimento advindos da sexualidade.

É a partir da experiência com o labor de produzir articulações contemporâneas das sexualidades, gêneros, orientações sexuais com a Psicanálise que o presente artigo se constitui. Parte-se da constatação do valor das contribuições freudianas como fundamentais ao pensamento psicanalítico, principalmente no que diz respeito à necessária abertura da Psicanálise às transformações que permitam mantê-la vigente em diferentes tempos sócio-históricos. Se as proposições freudianas são reflexos de sua época, torna-se crucial revisitar metapsicologicamente conceitos fundamentais de forma a separar o que é história e o que é operador teórico atual. Nesta proposta, o presente artigo tem por objetivo construir uma leitura psicanalítica possível para questões referentes à sexualidade, ao gênero e à orientação sexual distanciando-se de uma leitura heteronormativa e, até mesmo, patologizante, ainda tão comum no discurso psicanalítico.

\section{A psicanálise como herdeira do ideário moderno}

O interrogante central da construção do Laboratório de Sexualidade, Gênero e Psicanálise refere-se a como escutar distintas expressões da sexualidade, da orientação sexual e das performances de gênero. É inegável que são diversas e heterogêneas as produções de subjetividade sexuadas e, contemporaneamente, se está cada vez mais convidado a reconhecê-las, uma vez que saem da margem e do silenciamento e passam, felizmente, a ser sustentadas "a luz do dia". Para fazer trabalhar tal interrogante, é fundamental realizar uma crítica à patologização das sexualidades dissidentes, existente tanto na Psicologia, como na Psicanálise. Para tanto, recorremos a Foucault (1976/1988) e suas proposições acerca da apropriação da sexualidade pelo discurso médico, a fim de dominar o sexo, a sexualidade e os corpos. 
A Modernidade, sustentada nos dispositivos repressores da Biologia e da Medicina, constrói um tipo de discurso a respeito do sujeito que coloca a sexualidade como um vetor decisivo na produção de subjetividade. Neste mesmo cenário, a heterossexualidade é inventada e passa a ocupar o lugar de norma - forma esperada de relação afetiva entre os sujeitos. Como destacam Carvalho e Oliveira (2017), "na era vitoriana, a moral burguesa conduziria a sexualidade para o seio da família conjugal heterossexual, legitimando-a por meio da função reprodutora, imposta como modelo e discurso de verdade" (p. 102). Logo, qualquer outro processo de subjetivação que não este - sustentado no saber médico, organizado pela lógica binária da cis-heteronormatividade - questiona não apenas o discurso dominante, senão também outras estruturas fundamentais, tais como a família, por exemplo, por meio dos tensionamentos dos regimes de conjugalidade, parentesco, filiação e reprodução.

De fato, Foucault (1984) denuncia a existência da íntima relação entre a repressão sexual e as relações de poder. Afinal, a repressão sexual tornou-se necessária para garantir o exercício de poder desde os parâmetros da ordem social burguesa. Assim, no Ocidente, "se formou uma ciência sexual que produz discursos de verdade sobre a sexualidade. No saber médico, enuncia-se uma verdade acerca da sexualidade. Há uma opressão do sexo e de práticas consideradas desviantes da norma por discursos que estabelecem relações de poder/saber" (Carvalho, \& Oliveira, 2017). Logo, sujeitos associados a práticas sexuais consideradas desviantes são caracterizados pelos discursos da Medicina como casos patológicos ou anomalias.

A Psicanálise, sabe-se, é herdeira deste ideário moderno. Nesta direção, as construções acerca da Sexualidade também se mostram - muitas vezes associadas a esta concepção ideológica. Em Freud, há uma compreensão binária e cis-heteronormativa, a qual restringe a compreensão das produções subjetivas sexuadas. A clínica pode tornar-se um dispositivo de violência quando se sustenta uma escuta calcada na norma patriarcal e se trabalha, tentando encaixar um sujeito dentro de duas possibilidades de experiência da sexualidade. A escuta psicanalítica vem reproduzindo este modelo de violência ao patologizar os arranjos de sexualidade e de gênero que foram excluídos na Modernidade.
É necessário, então, revisitar a metapsicologia psicanalítica de forma a fazer trabalhar parâmetros conceituais e técnicos para manter a potência e a vitalidade da escuta psicanalítica. Afinal, em Freud não existe apenas a ideologia cis-heteronormativa. Também há operadores conceituais muito potentes para a escuta e a compreensão da sexualidade humana em suas complexas expressões. Toma-se a proposta de Blestcher ${ }^{1}$ (2019) como eixo principal nesta revisitação: contemporaneamente, não é mais importante a questão sobre o que os psicanalistas têm a dizer a respeito das dissidências sexuais, mas o que as dissidências sexuais dizem aos psicanalistas. Não se trata, pois, de construir uma nova teoria para o entendimento das diferentes expressões de sexualidade e gênero, mas, sim, de efetivamente escutá-los e de colocar nossas concepções teóricas a prova, de tal forma a revisar alguns pontos nodais, como, por exemplo, a tendência a patologizar o que foge de uma composição sexual da "norma" heterossexista, heteronormativa e falocêntrica.

\section{Produção subjetiva como hipersingular}

A invenção do conceito de "identidade de gênero" foi do psicanalista americano Robert Stoller, no ano de 1964 (Porchat, 2014), quando realizava o acompanhamento e tratamento de pacientes transexuais e seus pais. No clássico livro "Sex and Gender", Stoller (1968, citado por Roudinesco, \& Plon, 2001) trabalha a ideia de gênero como um conceito que permite diferenciar de forma contundente o sexo - como determinação orgânica do homem e da mulher - do sentimento social de identidade. O gênero contempla, assim, o "sexo social". Cossi (2018) esclarece que, na teorização de Stoller, sexo diz respeito à biologia (genética, caracteres primários e secundários do sexo, aparato anatomofisiológico, endócrino e cerebral), enquanto gênero se refere ao conjunto de comportamento, sentimentos, pensamentos e fantasias relacionados à masculinidade e à feminilidade, não sendo ancorados pela biologia, mas, sim, consolidados culturalmente. Logo, "sexo e gênero não andam necessariamente lado a lado; um pode se desenvolver a despeito do outro" (p. 32).

Destaca Porchat (2014), contudo, que, mesmo que tenha surgido como nova proposta que questiona o uso excessivamente anatômico de termos clássi-

${ }^{1}$ Blestcher, F. (2019). As múltiplas formas da sexualidade: O estranho em nós. In Centro de Estudos Psicanalíticos de Porto Alegre. Aula inaugural do curso de formação em psicanálise. Porto Alegre, RS: o autor. 
cos como "Angústia de Castração", as proposições de Stoller sempre estiveram ligadas à psicopatologia, por meio do estudo do transexualismo. Desta forma, em sua obra, subsistia a expectativa de que houvesse, no curso do desenvolvimento, a coerência do sexo anatômico e do gênero.

As relações entre Psicanálise e gênero se modificam quando Butler (1990/2018) publica "Problemas de Gênero", questionando a ideia de um núcleo de identidade de gênero e ressaltando a imposição de uma ordem binária, ancorada numa matriz heterossexual. Interroga Butler "que configuração de poder constrói o sujeito e o Outro, essa relação binária entre 'homens' e 'mulheres', e a estabilidade interna desses termos?" (p. 8). "O que acontece ao sujeito e à estabilidade das categorias de gênero quando o regime epistemológico da presunção da heterossexualidade é desmascarado, explicitando-se como produtor e reificador dessas categorias ostensivamente ontológicas?" (Butler, 1990/2018, p. 8).

Butler, filósofa feminista, apresenta seus questionamentos em relação à divisão binária das identidades que ainda rege a sociedade. Parte de uma concepção de sujeito que não determina, à priori, uma noção de normalidade e patologia a partir das identidades de gêneros binárias. Propõe gênero como ato performativo e os entende como os "inteligíveis" e os não inteligíveis”. Os inteligíveis apresentariam uma coerência entre sexo, gênero, prática sexual e desejo (Butler 1990/2018).

Porchat (2014), embasada em sua desconstrução de gêneros e de patologias com Judith Butler, sustenta que uma Psicanálise que se proponha a escutar os gêneros minoritários deve, necessariamente, ressignificar as categorias metapsicológicas de "mulher", "homem", "complexo de Édipo", "diferença sexual" e "simbólico". Conceitos que são eminentemente produzidos a partir de circunstâncias de parentesco e de linguagem históricas, mas que, ao serem elevados a uma categoria transcendental e imune a transformações, permitem que certa Psicanálise categorize sem pestanejar sujeitos fora da norma sexo/gênero como psicóticos ou perversos dentro de sua nosografia.

Neste cenário, corrobora-se a proposição de Porchat (2014) acerca da necessidade de reformulação de pressupostos psicanalíticos que estão colocados como fenômenos universais e transcendentais e, portanto, normativos, "pretensamente imunes às transformações da sociedade, advogando para si o direito de impor regras de inteligibilidade cultural" (p. 157). Neste percurso, desde Foucault a Butler, Porchat (2014) sustenta que, se a divisão binária de gêneros era um fundamento necessário ao laço social outrora, isso não mais se mantém vigente na contemporaneidade (Porchat, 2014).

Nesta mesma direção, Ayouch (2015) ressalta a grande diferença existente entre tratar os ideais e teorias como construções culturais - portanto sujeitos a desconstruções e reconstruções - e tratá-los como verdades absolutas, universais e transcendentais. Além da proximidade com o discurso religioso, uma Psicanálise que se fecha às evoluções históricas e clínicas nos parece reduzir-se a um processo narcísico e autoerótico do teorizador (Rodrigues, 2016).

Daí decorre a necessidade de retomarmos o preceito psicanalítico que de qualquer produção subjetiva é singular - hipersingular - devendo "ser escutada sempre com o interesse de quem escuta algo novo. É a experiência clínica que deve fomentar as discussões e teses metapsicológicas, e não estas quem devem moldar de maneira violenta um sujeito para que caiba em seus paradigmas". (Rodrigues, 2016, p. 176). No mesmo sentido, entende-se que a questão fundamental dos psicanalistas hoje não é apresentar respostas definitivas a questão das apresentações de sexualidades e gêneros, mas, sim, sustentar os interrogantes levantados e abrir novas questões. Tem-se dessa maneira uma multiplicidade de perguntas o que implica sair de uma posição confortável com respeito ao saber (Fiorini, 2015).

Questionar a patologização das experiências sexuais humanas não é, contudo, sustentar a ausência de psicopatologia. Arranjos psíquicos podem se dar no âmbito da psicopatologia. Acreditamos na existência dos arranjos que aprisionam, produzem dor, sofrimento, inibições e angústia. E para que haja uma concepção psicanalítica de saúde e de patologia é inevitável que haja norma. Não parece haver possibilidade de existir teoria, avaliação, classificação e compreensão sem norma. A questão passa a ser qual é a norma desde onde se sustenta a escuta e a teoria psicanalítica do sujeito. Para buscar respostas a esta questão, parte-se da premissa sustentada por Blestcher (2017) de que "o quadro identitário no que o sujeito se instala deve ser respeitado como condição de estabilidade estrutural e só interrogado quando seu equilíbrio se encontra em risco ou empobreça suas melhores possibilidades de realização subjetiva" (p. 82). 
No que se refere às questões que tratam da norma e da patologização, Jorge e Travassos (2017) na sua publicação "A epidemia transexual: histeria na era da ciência e da globalização" enfrentaram críticas por questionar o sofrimento psíquico e sua possível roupagem na transformação biológica. Os autores propuseram que, se no início se "concebeu a transexualidade como uma forma sintomática da psicose, hoje fica claro que nem toda transexualidade é psicótica. Ao contrário, hoje a histeria parece ter se apropriado da transexualidade para postular sua perene pergunta sobre a verdade do sexo" (p. 318).

Os mesmos autores, numa posterior publicação, ressaltaram que a partir da Psicanálise, que toma todo caso como absoluta particularidade, "qualquer experiência transexual é estritamente singular, sendo impossível sua compreensão a partir da generalização psicológica, seja ela a mais sofisticada que for" (Jorge,\& Travassos, 2018, p. 13). Se cada sujeito é uma constelação simbólica única, é inconcebível entendê-lo como um fato psíquico geral.

\section{Sexualidade infantil, gênero e escolha objetal}

Embora Freud não tenha usado a expressão "identidade de gênero", ele se ocupava desse tema quando propunha encontrar uma explicação do desenvolvimento da masculinidade e da feminilidade em homens e mulheres. Isso ocorreu num tempo anterior à separação entre sexo e gênero proposta por Stoller (Porchat, 2014). Alguns textos freudianos buscaram esclarecer quanto à transformação, ou não, do menino num homem masculino e da menina, numa mulher feminina, tais como "A dissolução do Complexo de Édipo" (1976b), "Algumas consequências psíquicas da diferença anatômica entre os sexos", (1976c), "A sexualidade Feminina" (1976d) e "Feminilidade" (1976e). Com suas proposições, Freud mostrou que esse percurso não era natural, e muito menos óbvio (Porchat, 2014).

Em Freud a noção de psicossexualidade refere-se à compreensão de um processo progressivo em essência, porém não linear, de complexização psíquica. No ponto de origem está o autoerotismo e o polimorfismo parcial das pulsões. Na trama das complexizações da psicossexualidade residem os desafios de construção de uma identidade sexual e de eleições objetais. Sabemos que as identidades trans e as diversas subjetivações sexuadas põem em xeque o caráter binário das concepções psicanalíticas, exigindo, conforme Blestcher (2017), retomar premissas que fundam a teoria da diferença sexual. Para isso, é necessário resgatar o caráter pulsional da sexualidade infantil: "mais do que o infantilismo da sexualidade, se trata de recuperar a sexualidade infantil em seu caráter pulsional. E, a partir daí, identificar processos de ligação e 'fantasmatização' que vão organizando seus destinos no sujeito psíquico" (p. 75).

$\mathrm{O}$ autor adverte, porém, que a diversidade das identidades sexuais não pode ser confundida com o caráter polimórfico da sexualidade infantil. Nos Três Ensaios, Freud (1976a) trabalha com uma variedade de formas das pulsões sexuais infantis que encontram sua satisfação sem consideração ao objeto. A condição perversa neste tempo diz respeito à pulsão e não ao sujeito e muito menos às formas identitárias que se articulam ao gênero e ao reconhecimento das diferenças entre os sexos.

Tampouco, para Blestcher (2017), a diversidade das identidades sexuais encontra na concepção de bissexualidade uma sustentação teórica. Afinal, as pulsões não são homo ou heterossexuais: "Os fantasmas são homo e heterossexuais para o eu, não em si mesmos". (Bleichmar, 2014, p. 288). As pulsões ativadas no Inconsciente não se distinguem, já que lá não há princípio de diferença, oposição ou contradição. Somente secundariamente o Eu é capaz se qualificar tais moções sexuais em termos homo ou heterossexuais, a parir de constelações discursivas que permitem sua captura nas redes de significação. As primeiras experiências de prazer estão organizadas, na leitura de Bleichmar (2014), pelo autoerotismo, no qual não há a inscrição da diferença sexual. Somente no momento em que a diferença se inscreve é que o Eu pode (re)organizar os desejos primários como homo ou heterossexuais.

Assim, o elemento organizador do autoerotismo será o Eu. A construção da identidade sexual, identidade de gênero e das eleições objetais vão referir-se a uma história pulsional polimórfica mediadas por enunciados identificatórios provenientes do imaginário parental. Tomando as proposições de Dejours (2003), Blestcher (2017) argumenta que por meio de uma atribuição de gênero, o adulto, sabendo ou não, confronta a criança com tudo o que pode haver de ambíguo na diferença entre os sexos e no sexual, por suas próprias ambivalências, incertezas e conflitos internos. Assim, "a atribuição de gênero não é uma 
simples determinação social transmitida pela instância parental, nem se acha somente determinada por suas constelações narcísicas, senão que está comprometida pela sexualidade inconsciente do outro enquanto sujeito clivado" (Blestcher, 2017, p.80).

Portanto, considerar a complexa construção da sexualidade, sexo, gênero e sexuação convida a uma reflexão a respeito ao estatuto do sexual nas origens do sujeito psíquico e nos destinos de sua constituição (Blestcher, 2017, p. 82). Entende-se ser premissa básica da Psicanálise - que se propõe crítica - romper com noções binárias de sexuação e historicizar suas próprias ferramentas de análise. Assim, produz-se uma desconstrução fundamentalmente psicanalítica da própria psicanálise, que, "ao invés de respaldar uma patologização paralisante das experiências transidentitárias, pode fomentar críticas à normalização e às formas como o poder social e o preconceito se inscrevem, muitas vezes violentamente, na psique e nos corpos" (Ayouch, 2015, p. 69).

Ayouch (2015) sustenta, pelo polimorfo processo de produção do Eu- via identificação-, que o sujeito se constrói e se transforma a partir do outro, apropriando-se de elementos distintos dos seres ao seu entorno. A identificação é operação fundamental à construção da subjetividade. Isso quer dizer que, de acordo com o estatuto metapsicológico, quando se coloca luz sobre a multiplicidade psíquica e as camadas de conflitos, sobre a pulsão e a dinâmica psíquica, deixa de ter sentido a manutenção da leitura enrijecida de masculinidade e feminilidade e a diferença binária entre os sexos.

Partindo dessa organização do Eu e das diversas formas da apresentação de sexualidade e gênero, Fiorini (2015) propõe alguns desdobramentos na estruturação metapsicológica. A autora acredita que é necessário sustentar o conceito da diferença sexual como condição de acesso ao universo simbólico, assim como o conceito de castração. Além disso, a Psicanálise deve, a partir das manifestações diversas da sexualidade, questionar os significados da polaridade binaria masculina-feminino e suas incertezas. Por fim, ao descentralizar os gêneros clássicos masculinos e femininos, questiona-se a figura ideal do casal heterossexual e da família nuclear clássica.

Estas problematizações apontam para o tema da identidade sexual, gênero e escolha objetal que são construções sustentadas pela Psicanálise e que se relacionam mutuamente. A partir da proposição de Muszkat (2011), a identidade sexual refere-se à noção construída subjetivamente pelo indivíduo, que passa a sentir-se sexuado, dotado de desejo e vai em busca de práticas que possam atender seu mundo desejante. A identidade sexual não define os esquemas de gênero, mesmo que possam manter uma relação próxima. Já a identidade de gênero se inscreve mais diretamente a uma lógica de valores adotados na cultura o que muitas vezes impede que a sexualidade seja exercida de acordo com o que é legítimo do indivíduo. Sinteticamente, Muszkat (2011) propõe, ainda, que a identidade sexual pode ser considerada uma noção de si mesmo, que possibilita maior grau de liberdade do sujeito, e o gênero diz respeito às expressões e performances de gênero.

Sustenta-se, assim, que a identidade sexual é um processo mais amplo que a construção da identidade de gênero. E, provavelmente por isso, é um processo tão caro à Psicanálise. A identidade sexual conta dos arranjos de investimentos da economia sexual do sujeito, desde um corpo erógeno, uma vez que é o Eu tal como vê a si mesmo e ao mundo que é capaz de organizar e construir vias de acesso ao prazer, às relações e à ocupação de distintas posições subjetivas no mundo. A identidade de gênero, de forma mais específica, refere-se a uma sustentação por parte do sujeito de um conjunto de concepções e, consequentemente, de práticas do gênero ao qual ele se identifica.

Já a escolha objetal parte de um complexo processo psíquico que inicia na importante inscrição da pulsão pelo objeto no sujeito, os enunciados identificatórios, a conquista de um lugar frente ao outro e a posterior quebra das certezas da completude. É justamente nesse momento de quebra do paradigma do ser pleno que passa a se inscrever a possibilidade das diferenças e da alteridade. Isso quer dizer que, ao ser atravessado pela incompletude, o sujeito passa a construção de uma identidade e de uma escolha de objetos que sustentem o outro com o estatuto da diferença.

Vale lembrar o que diz Porchat (2014), propondo que exista uma distinção importante entre "identidade" e "identificação". Enquanto identidade se refere à formação de gênero, a identificação em Psicanálise é utilizada para definir a atividade inconsciente de construção e transformação do Eu. É de todo o sujeito a tarefa da constituição da identidade. Talvez essa seja uma das tarefas mais complexas e difíceis, por isso é preciso que se percorra um longo caminho para construí-la. O reconhecimento das diferenças como organizador da incompletude do outro e do Eu 
é imprescindível na construção das relações de desejo do sujeito com o objeto. É a percepção das diferenças que possibilita as interrogantes: Quem sou eu? Qual o objeto do meu desejo? Na quebra do narcisismo infantil- com sua ilusão de completude e de pleno e irrestrito acesso ao prazer- por meio do reconhecimento da exclusão e da interdição que ao sujeito abre espaço um intenso trabalho psíquico de reconstrução narcísica frente às diferenças. Isso implica reorganizar que sou eu, qual meu valor e onde invisto no campo das diferenças e da alteridade.

Para Blestcher (2017), a identidade de gênero como todo enunciado de identidade - corresponde uma tópica do Eu. A tarefa da construção de gênero remonta às propostas identificatórias que partem da fantasmatização dos atributos sexuais do imaginário parental. Tal atribuição é da ordem da cultura e não é determinada exclusivamente pela biologia (ou anatomia), senão por um conjunto de significações. Do lado do psiquismo infantil, a construção de gênero é anterior ao reconhecimento da diferença anatômica entre os sexos. O Eu é constituído em relação com a instauração do recalque originário que funda o Inconsciente. Porchat (2018) argumenta que se pode considerar a constituição do gênero por meio das identificações, não a partir de um estado anatômico (pré)determinante. Contudo, esse anatômico serve de base para o gênero social que se cria em cima dele: os homens e mulheres sociais.

Nesse sentido, as significações ofertadas podem ser entendidas como um projeto identificatório, tal como proposto por Aulagnier (1968/1990), isto é, os "enunciados sucessivos pelos quais o sujeito define (para si e para os outros) seu anseio identificatório, ou seja, seu ideal" (p. 214). Ao instalar o projeto identificatório no $\mathrm{Eu}$, as questões sobre o si mesmo já não são respondidas por um outro, mas, sim, pelo próprio $\mathrm{Eu}$, a partir de sua história.

Entende-se, assim, que o Eu se sustenta como um conglomerado representacional no qual os atributos de gênero ainda têm uma posição central. Cada sujeito se localizará numa das categorias sociais de uma época, produzindo a sua construção subjetiva. Torna-se evidente que esse processo não esgota uma sexualidade pulsional, cuja regulação se verifica como incansável (Blestcher, 2017).

Sendo assim, os enunciados que terão que ser configurados na identidade de gênero, por via de uma identificação primária, configuram conteúdos nucle- ares da representação egóica. Para Fiorini (2015), o gênero também faz parte dos processos de subjetivação e no campo psicanalítico se apresenta na forma de ideais identificatórios, no eixo Eu Ideal - Ideal do Eu, eixo imaginário, mas com forte efetividade simbólica.

$\mathrm{O}$ processo de identificação pode ser entendido como a operação fundamental que dá origem as condições para instituir a subjetividade. É sobre o processo de identificação que se estrutura a base da identidade com um conjunto de enunciados que permitem o sujeito conhecer a si mesmo como um marco do enlace libidinal ao semelhante. Percebe-se que meninos e meninas não se identificam com o objeto real, senão ao projeto e formas representacionais com o que se organiza a circulação simbólica e libidinal com adultas e adultos (Bleichmar, 1995 citado por Blestcher, 2017, p. 81).

\section{SexualidadeS: feminilidades, masculinidades, homossexualidades, transexualidades}

A construção de identidade se apoia nos enunciados primários ofertados pelos objetos cuidadores, os quais são, também, representantes da cultura. Sendo a ordem social moderna binária, cada sujeito é convocado a assumir uma performance frente ao outro, que não necessariamente está de acordo com únicas duas categorias da experiência humana, masculino e feminino. Logo a questão "quem eu sou?" toma uma dimensão muito mais ampla e complexa.

Ocorre que, a Modernidade acentuou uma divisão nítida entre masculino e feminino, a pós-modernidade apresenta uma pluralidade e multiplicidade dos processos de subjetivação e de exercícios da sexualidade. Estes dois discursos contraditórios coexistem nas culturas atuais (Fiorini, 2015) e ficam evidentes nas escutas clínicas.

De fato, Fiorini (2010) auxilia a problematizar essa reflexão quando utiliza a noção de sexualidades nômades, deslocamentos, migrações e fluxos dos itinerários do desejo, mais além da norma heterossexual pré-fixada. Ao se referir aos transgêneros, está tratando de ir mais além das determinações clássicas dos gêneros masculinos e femininos. A autora toma o termo transexualidade no sentido amplo - como atravessamento de barreiras - e não como uma referência estrita à transexualidade como problemática conflitiva de gênero. Faz referência a uma variedade de subjetividades que não se encontram na dicotomia 
masculino/feminino e que são conhecidas também como apresentações queer ou diversidades sexuais e de gênero. A proposta é, assim, tomar as transexualidades como um significante de múltiplos significados. Nenhum dos termos abarca por si só a totalidade destas apresentações, cada um enfoca distintos aspectos deles mesmos. É preciso, pois, ressaltar a heterogeneidade das hipersingularidades que produzem Sexualidades: feminilidades, masculinidades, homossexualidades, transexualidades, enfim, uma conceitualização em plural, a qual destaca a impossibilidade de universalizar uma experiência tão singular.

A mesma autora propõe a lógica binária como insuficiente, apresentando contradições em si mesmas (Fiorini, 2015, p. 99). Tais contradições referem-se: 1) ao campo desejante, por sua multiplicidade, não se limita a uma lógica dualista; 2) às identificações, que são sempre plurais e contraditórias; 3 ) às identidades de gênero, as quais podem não coincidir com o corpo anatômico; 4) aos papéis de gênero que são fortemente questionados especialmente num mundo ocidental; 5) à eleição de objeto sexual não ser um fato natural.

Parece evidente considerar, então, que, para além de uma diferença que se instala pela diferença anatômica entre os sexos, o que efetivamente pode pôr em marcha processos identificatórios de construção de uma posição sexuada diz respeito à ocupação de uma posição subjetiva de que algo lhe falta. Uma posição sexuada existirá no campo da alteridade. E daí decorre uma questão central: como organiza-se a alteridade? Arán (2009), em sua discussão acerca do dispositivo da diferença sexual, sustenta que a possibilidade de reorganização metapsicológica que viabilize uma ruptura da Psicanálise com o paradigma binário cis-heteronormativo implica: 1) uma crítica à centralidade da ideia do Édipo e do complexo de castração na Psicanálise; 2) uma releitura da ideia de corpo erógeno na teoria freudiana com o objetivo de fundamentar metapsicologicamente a ideia de um excesso pulsional, o que, para a autora, é pressuposto fundamental para que se possa pensar a multiplicidade das experiências subjetivas; 3 ) uma abordagem dos processos de subjetivação que toma como base referências extraídas da estética, em que a diferença se expressa como singularidade.

Neste mesmo sentido, Birman (2016) aponta que a revolução sexual (revolução feminina, homossexualidades, transexualidades) atravessa a construção psicanalítica tensionando sua estruturação deman- dando novas leituras, principalmente porque estabelece uma crítica contundente ao modelo psicanalítico clássico calcado no Complexo de Édipo. Arán (2002) já havia sustentado que pensar a diferença como singularidade rompe com a leitura de pensar o contraste dos sexos e, logo, com a centralidade do modelo Édipo-castração.

Desta forma, para Arán (2009), propor uma nova abordagem da diferença é possível por meio do deslizamento entre a ideia de feminino e de singular, condensando o que sempre foi excluído pelo Ocidente, em nome do princípio de identidade. Para a autora, o maior desafio desta nova concepção diz respeito a afirmar a positividade do corpo feminino na sua diferença, "já que essa experiência foi historicamente recalcada ou mesmo expulsa do esquema simbólico dominante, sem pressupor que essa alteridade constitua um outro modelo (oposto ao masculino) e sim a afirmação de uma multiplicidade de singularidades" (p. 663).

Logo, enquanto as concepções de diferença e alteridade estiverem atreladas teoricamente à polaridade masculino/feminino elas serão reprodutoras da lógica binária e heteronormativa. Se por outro lado, a alteridade estiver sustentada no reconhecimento da existência de sexualidades diferentes - e não na diferença entre os sexos - abre-se a possiblidade de reconhecer como válidas e possíveis inúmeras amarrações sexuais de identidade e de escolha objetais. Disso se trata o reconhecimento da heterogeneidade das subjetividades sexuadas.

Consequentemente, passa a ser fundamental, para a autora, a Psicanálise estabelecer relações mais produtivas com as novas formas de construções de gêneros na cultura contemporânea, uma vez que, nelas, as diferenças, singularidades e alteridades estendem e subvertem os limites do simbólico e da própria teoria psicanalítica. Com isso, conforme Arán (2009), seria inevitável e imprescindível problematizar determinados temas, considerados tabu na teoria psicanalítica, promovendo diálogos com a "filosofia pós-metafísica - particularmente Foucault, Deleuze e Guatari -, o que permitiria a efetivação de uma crítica ao conceito de sujeito, ao lugar transcendente da lei e da figura paterna, como também o redimensionamento do corpo e dos afetos diante da primazia da linguagem" (Arán, 2009, p. 669).

A inscrição do registro de alteridade como elemento crucial para a abertura à diferença, convoca à consideração da hipersingularidade. Nessa mesma 
direção, Ayouch (2015) e Porchat (2014) propõem a troca da categoria "homossexualidade", idêntica a si mesma, por outra mais plural: "homossexualidades". Desde essa prerrogativa, os autores sustentam que as "transexualidades" podem ser tão variadas quanto a das cissexualidades. Logo, é preciso sustentar uma base teórica capaz de verdadeiramente dar espaço aos arranjos heterogêneos, complexos, plurais e singulares da sexualidade humana.

\section{Para criar vias colaterais...}

Se a Psicanálise se sustentou inicialmente sobre uma norma binária e cis-heteronormariva, hoje, quais seriam as normas que seguem vigentes e potentes na Psicanálise? Bleichmar (1999) trabalhou com a ideia de que a Psicanálise introduziu a sexualidade em duas formas, a pulsional e a de objeto. A partir desse constructo, é possível sustentar que a identidade sexual não se estabelece como desenlace da escolha de objeto. A identidade sexual se estrutura a partir de enunciados nucleares que organizam a instância egoica. Nesse sentido, considerar a complexa formação entre sexualidade, gênero e sexuação leva a pensar nas origens do sujeito psíquico e nos destinos de sua constituição.

Fica evidente com o que apresentamos até aqui, o grande impacto do reconhecimento da falta teórica e técnica da Psicanálise, que sustentada historicamente por uma lógica binaria e cis-heteronormativa, não pôde dar conta de compreender as múltiplas formas de exercício da sexualidade. Por outro lado, a (re) construção de normas, faz da Psicanálise um instrumento vigoroso na escuta de modos de sexualidade e produção de subjetividades. Apoiados em constructos fundamentais, propõe-se seguir com a sustentação metapsicológica da alteridade como acesso ao estatuto das diferenças nas relações do Eu e com os outros.

Para tanto, é preciso reconhecer a explícita violência de certas interpretações ditas psicanalíticas quando recorrem à lógica cis-heteronormativa e falocêntrica para validar o processo de sexuação do sujeito. Como destaca Ayouch (2015), para que a Psicanálise reencontre sua potência questionadora e transformadora, torna-se necessário o reconhecimento de que todo processo de sexuação sempre se inscreve em normatizações e jogos de poder particulares. Na direção das proposições de Rodrigues (2006, p. 178) "defende-se que, para manter-se psicanalítica, a Psicanálise não deve furtar-se da análise e do ques- tionamento daquilo que as normas produzem. Ao questionar a transcendentalidade da diferença sexual, posicionando-se politicamente, a Psicanálise pode denunciar o maltrato institucional, teórico e clínico" que as dissidências sexuais sofrem.

A clínica psicanalítica contemporânea convoca à complexidade dos registros de incompletude e a modos de subjetivação para alcançar a alteridade. A ética da Psicanálise segue sendo apoiar o sujeito no encontro com o seu próprio desejo, seja ele de qual organização sexual for. Para isso, é necessário que a teoria saia de uma organização cristalizada para uma organização viva e pulsante.

Logo, o diálogo com os estudos de gênero é proveitoso na medida em que permite considerar as formas com que se inscrevem os enunciados, mandatos e ideais que modelam a distinção entre masculino e feminino e são construídos segundo o imaginário histórico-social. Não trata-se de fazer uma distinção entre transexualidades e cis-heterossexualidades, mas sobretudo por em cena, em análise, o que é da classe de lugares comuns que tentam agrupar modos de subjetivação. Essa questão implica em suspender uma carga trazida historicamente pela Psicanálise e que hoje não pode mais dar conta de alguns fenômenos observados.

Por outro lado, é fundamental sustentar o paradigma psicanalítico que persiste nas transformações históricas e sociais com capacidade de escuta e de intervenção. Como toda a teoria se construí a partir de um pressuposto histórico, é inevitável que possamos seguir pensando em significações dessa época. Isso não recusa a teoria de Freud, mas trata-se de fazer um trabalho de depuração, separando o que persiste e o que pode mudar (Blestcher, 2019).

Num curso ministrado em 1991, Laplanche trabalhou o tema da Psicanálise precisar ser constantemente crítica e que isso não implica reduzi-la ou atacá-la. O autor foi questionado por colocar o equilíbrio do pensamento freudiano em risco e, então, respondeu "Seria ele um edifício, um belo edifício, do qual não se pode suprimir nenhuma ala, nenhuma parte? Deve-se aceitá-lo em bloco - para não ser herege assim como se aceitou durante séculos o pensamento aristotélico, e como se faz, em certos meios, com os textos sagrados?" (Laplanche, 1997, p. 9). Entende-se, ancorado na provocação laplanchiana que o diálogo com a cultura e com a clínica psicanalítica impulsionam novos estudos que possam manter o espírito 
freudiano de produção de conhecimento, oferecendo leituras e práticas que dêem conta das múltiplas formas de sexualidades.

É desta forma que se tem conduzido os modos de fazer do Laboratório de Sexualidade, Gênero e Psicanálise produzindo interrogantes e articulações contemporâneas das sexualidades, gêneros, orientações sexuais para com a Psicanálise. O entendimento de cada sujeito como singular - afastado das imposições históricas heteronormativas, heterossexista e falocêntrica - produz uma Psicanálise viva capaz de aproximar-se de alunos curiosos, reflexivos e críticos.
Para finalizar, apoia-se em Sigal (2017) que propõe que, para a Psicanálise se manter viva é necessário pensar novas formas de produção de conhecimento que possam "incorporar o novo e reorganizar o já conhecido” (p. 35). Sustenta a autora, ainda, ser importante que não se tome a teoria como um corpo morto, coagulado ou estagnado. Defende que é trabalhando e aprofundando a Psicanálise que conseguiremos avançar embora perceba que, no campo da Psicanálise, exista certa confusão para pensar o modo como se incorporam os novos conhecimentos.

\section{Referências}

Arán, M. (2002). Feminilidade: Alteridade e experiência. Physis: Revista de Saúde Coletiva, 12(1), 121-140. https://doi.org/10.1590/S0103-73312002000100008

Arán, M. (2009). A psicanálise e o dispositivo da diferença sexual. Estudos Feministas, 17(3), 653-673.

Ayouch, T. (2015). Da transexualidade às transidentidades: Psicanálise e gêneros plurais. Percurso, 54(1), 23-32.

Berlinck, M. T. (2000). Logos. Cadernos de Psicologia UFMG, 10, 105-116.

Birman, J. (2016). Sexo e gênero. In XV Jornada - O sexo que habito, do Espaço Brasileiro de Estudos Psicanalíticos, Rio de Janeiro, RJ, Brasil, 15. Recuperado de https://www.youtube.com/watch?v=kaNHGzI56Xc

Bleichmar, S. (1999). A fundação do inconsciente: Destinos da pulsão, destinos do sujeito. Porto Alegre, RS: Artes Médicas

Bleichmar, S. (2014). Las teorias sexuales em psicoanálisis: Que permanece de ellas en la prátictica actual. Buenos Aires: Paidós.

Blestcher, F. (2017). La sexualidad infantil más acá del género y de la sexuácion: extravios y encaminamientos de la teoria sexual. In R. M. Garcia (Org.), Sobre o infantilismo da sexualildade (pp.63-84). Porto Alegre, RS: Sulina.

Butler, J. (2018). Problemas de gênero: Feminismo e subversão da identidade. Rio de Janeiro, RJ: Civilização Brasileira. (Obra original publicada em 1990).

Carvalho, G. P., \&Oliveira, A. S.Q. (2017). Discurso, poder e sexualidade em Foucault. Revista Dialectus, 4(11), 100-115. https:// doi.org/10.30611/2017n11id31003

Cossi, R. K. (2018). Stoller e a psicanálise: Da identidade de gênero ao semblante lacaniano. Estudos de Psicanálise, (49), 31-44.

Dejours, C. (2003). Pour une théorie psychanalytique de la difference des sexes. Libres Cabiers pour la Psychanalyse, 8, 55-67.

Fiorini, L. G. (2015). La diferencia sexual em debate: Cuerpos, deseos y ficciones. Buenos Aires: Lugar.

Fiorini, L. G. (2010). Sexualidades nômades y transgenero: Un desafio a la polaridade masculino/feminino. In B. Zelcer (Org.), Diversidade sexual (57-76). Buenos Aires: Lugar.

Foucault, M. (1988). História da sexualidade I: A vontade de saber. Rio de Janeiro: Edições Graal, 1988. (Obra originalmente publicado em 1976)

Foucault, M. (1984). Microfísica do poder. Rio de Janeiro, Graal, 1984.

Freud, S. (1976a). Três ensaios sobre a teoria da sexualidade. Edição Standart das Obras Completas de Sigmund Freud. (Vol. 5, pp 121-252). Rio de Janeiro, RJ: Imago. (Obra originalmente publicada em 1905).

Freud, S. (1976b). A dissolução do Complexo de Édipo. In Freud, S. Edição standart das obras completas de Sigmund Freud (Vol. 19, pp 215-224). Rio de Janeiro, RJ: Imago. (Obra originalmente publicada em 1924). 
Freud, S. (1976c). Algumas consequências psíquicas da diferença anatômica entre os sexos. In Freud, S. Edição standart das obras completas de Sigmund Freud (Vol. 9, pp. 303-320). Rio de Janeiro, RJ: Imago. (Obra originalmente publicada em 1925).

Freud, S. (1976d). A sexualidade feminina. In Freud, S. Edição standart das obras completas de Sigmund Freud (Vol. 21, pp. 257-279). Rio de Janeiro, RJ: Imago. (Obra originalmente publicada em 1931).

Freud, S. (1976e). Feminilidade. In Freud, S. Edição standart das obras completas de Sigmund Freud (Vol 22, pp. 139-165). Rio de Janeiro, RJ: Imago. (Obra originalmente publicada em 1933).

Hornstein, L. (2009). Narcisismo: Autoestima, identidade, alteridade. São Paulo, SP: Via Lettera.

Jorge, M. A. C., \&Travassos, N. P. (2017). A epidemia transexual: Histeria na era da ciência e da globalização. Revista Latinoamericana de Psicopatologia Fundamental, 20(2), 307-330. https://doi.org/10.1590/1415-4714.2017v20n2p307.7

Jorge, M. A. C., \& Travassos, N. P. (2018). Transexualidade: O corpo entre o sujeito e a ciência. Rio de Janeiro, RJ: Zahar.

Laplanche, J. (1997). Freud e a sexualidade: O desvio biologizante. Rio de Janeiro, RJ: Jorge Zahar.

Muszkat, S. (2011) Violência e masculinidade (Coleção Clínica psicanalítica). São Paulo, SP: Casa do Psicólogo.

Porchat, P. (2014) Psicanálise e transexualismo:Desconstruindo gêneros e patologias com Judith Butler. Curitiba, PR: Juruá.

Porchat, P (2018). Barulhos de gênero. In C. Fraçoia, P. Porchat, \& P. Corsetto (Orgs.), Psicanálise e gênero: Narrativas feministas e queer no Brasil e na Argentina (pp.35-43). Curitiba, PR: Calligraphie.

Rodrigues, G. V. (2016). Escutando transidentidades na psicanalise: Potencialidades subversivas. Revista Periódicus, 5(1), 171-184. https://doi.org/10.9771/peri.vli5.17183

Sigal, A. M. (2017). Ainda a psicanálise no campo da sexuação. Estudos de Psicanálise., 47, 35-46.

Stoller, R. (1968). Sex and gender. The development of masculinity and femininity. New York, NY: Science House.

\section{Luciana Balestrin Redivo Drehmer}

Psicóloga, Psicanalista, Professora do Curso de Graduação em Psicologia da Escola de Ciências da Saúde e da Vida da Pontifícia Universidade Católica do Rio Grande do Sul (PUCRS), Porto Alegre- RS. Brasil.

E-mail: luciana.redivo@pucrs.br

(iD) https:// orcid.org/0000-0003-4482-1399

\section{Carolina Neumann de Barros Falcão}

Psicóloga, Psicanalista, Professora Adjunta do curso de Graduação em Psicologia da Escola de Ciências da Saúde e da Vida da Pontifícia Universidade Católica (PUC-RS), Porto Alegre - RS. Brasil.

E-mail: carolina.falcao@pucrs.br

iD https://orcid.org/0000-0002-0226-251X

Endereço para envio de correspondência:

Av Ipiranga, 6681 - Prédio $11-8^{\circ}$ andar

Escola de Ciências da Saúde e da Vida

Recebido 11/09/2019

Aceito 04/ 10/2019

Received 09/11/2019

Approved 10/04/2019

Recibido 11/09/2019

Aceptado 04/10/2019 
Como citar: Drehmer, L. B. R.; Barros-Falcão, C. N. (2019). Para Além da Concepção Binária Cis-heternormativa: a Psicanálise Interrogada pelas Diversidades Sexuais e de Gênero. Psicologia: Ciência e Profissão, 39 (n.spe 3), $62-74$. https://doi.org/10.1590/1982-3703003228536

How to cite: Drehmer, L. B. R.; Barros-Falcão, C. N. (2019). Beyond the binary and cis-heteronormative conception: psychoanalysis interrogated by sexual and gender diversities. Psicologia: Ciência e Profissão, 39 (nspe.3), 62-74. https://doi.org/10.1590/1982-3703003228536

Cómo citar: Drehmer, L. B. R.; Barros-Falcão, C. N. (2019). Mas allá de la concepción binaria cisheternormativa: el psicoanálisis interrogado por la diversidade sexual y de género. Psicologia: Ciência e Profissão, 39 (nspe.3), $62-74$. https://doi.org/10.1590/1982-3703003228536 